\title{
Região, desenvolvimento regional e turismo comunitário
}

\author{
Luria Neide Coriolano \\ Programa de Pós Graduação em Geografia e Mestrado Profissional em Gestão de Negócios Turísticos da \\ Universidade Estadual do Ceará (UECE) \\ Fábio Perdigão Vasconcelos
}

Programa de Pós-Graduação em Geografia da Universidade Estadual do Ceará (UECE)

Recebido: 07/12/2012 Versão revisada (entregue): 18/03/2013 Aprovado: 23/03/2013

\begin{abstract}
Resumo
Neste estudo, repensam-se região, desenvolvimento regional e comunidades, pelo exame de questões voltadas à solidariedade e às resistências sociais nas relações com turismo e territórios. Busca-se entender a importância do turismo no desenvolvimento regional e local, a contribuição na geração do trabalho e na práxis social nas regiões e nos núcleos receptores de turismo, aproximando-se de microterritórios, aqui chamados de comunidades. O artigo aborda o interesse por realidades regionais por meio do desenvolvimento regional que valoriza políticas locais no mundo globalizado. São pensadas possibilidades para o turismo de comunidades que, ao resistirem ao modelo hegemônico, exercitam alternativas de desenvolvimento. Levam-se em conta as especificidades locais no processo de planejamento, daí não se adotar modelo pronto, preconcebido, o que significa dizer que o turismo pode ser indicado para um lugar e para outro não. Problemas regionais diversos esperam soluções. A acelerada redução do trabalho, na forma de desemprego e exclusão aponta para nova proposta de desenvolvimento regional, do nível proposto neste trabalho, que exige redução de disparidades regionais e opções de práticas participativas, democráticas, e mecanismos para articulação de sujeitos sociais, priorizando pequenas escalas regionais.
\end{abstract}

Palavras-chave | Desenvolvimento regional; lugar; região; território turístico; turismo.

Código JEL | L83; O18; R10.

\section{REGION, REGIONAL DEVELOPMENT AND COMMUNITY TOURISM}

\begin{abstract}
In this study, region, regional development and communities are rethought by examining issues of sympathy and social resistance in relations with tourism and territories. We seek to understand the importance of tourism in regional and local development, its contribution to employment generation and social praxis in touristic regions and tourism centers in these areas from the approximation of micro-territories here called communities. In the article interests is shown in regional realities by means of regional development that values local policies in a
\end{abstract}


globalized world. Possibilities for tourism communities are thought that, while resisting the hegemonic model, can offer development alternatives. We take into account local specificities in the planning process, hence we chose not to adopt an already existing model, preconceived, which means that tourism can be adequate for a place and not for another. Many regional problems wait for solutions. The accelerated reduction of labor, in the form of unemployment and exclusion, points to a new proposal of regional development (as advocated in this study), which calls for reducing regional disparities and options of participatory practices, and democratic mechanisms for the articulation of social subjects, prioritizing small regional scales.

Keywords | Regional development; place; region; tourist territory; tourism.

JEL-Code | L83; O18; R10.

\section{REGIÓN, DESARROLLO REGIONAL Y TURISMO COMUNITARIO}

\section{Resumen}

En este estudio son repensadas las nociones de región, desarrollo regional y comunidad mediante el examen de fenómenos de resistencia y de solidaridad social relacionados con el turismo y los territorios. Se ha buscado entender la importancia del turismo en el desarrollo regional y local, su contribución en la generación de empleo, y su influencia en la praxis social en regiones y núcleos receptores de turismo. Esta problemática se ha desarrollado a partir de un abordaje de micro territorios, considerados aquí como comunidades. En el artículo se expresa interés en las realidades regionales a través del desarrollo regional que valore políticas locales articuladas con el mundo globalizado. Son pensadas posibilidades para el turismo de comunidades que, en la medida en que resisten al modelo hegemónico, ejercitan alternativas de desarrollo. El trabajo lleva en cuenta las especificidades locales en el proceso de planificación, lo que resulta en la recomendación de no adoptar modelos preestablecidos y en el reconocimiento de que el turismo puede ser recomendado para ciertos lugares y no para otros. El trabajo defiende una reducción de las disparidades regionales a través de opciones participativas y democráticas, y de mecanismos de articulación de sujetos sociales priorizando pequeñas escalas regionales.

Palabras-clave | Desarrollo regional, lugar, región, territorio turístico, turismo.

Código JEL | L83; O18; R10.

\section{Introdução}

Região é uma forma de compartimentar e gerir espaço em escala macro, meso ou micro para promoção do desenvolvimento socioeconômico e, assim, há regiões continentais, na escala de país, estado ou município, sendo um produto geográfico, histórico e cultural. No entanto, cada vez mais, a escala regional tende a diminuir, em contraponto a global; a globalização, porém, não extingue o regional. Local significa escala e o espaço onde se mora é que se denomina lugar. Região é a porção de dado território com indicadores e potencialidades naturais e culturais similares, integrados em usos e atividades econômicas. É um conceito de 
região voltado aos aspectos naturais, em especial ao clima, relevo e vegetação, mostrando que as atividades humanas dependem do ambiente natural. Teorias e conceitos de região avançam e retrocedem: descarta-se região, retoma-se e se redefine espaço e ideias, podendo-se afirmar que há pluralidade de abordagens e de teorias sobre regiões, com predomínio das geográficas.

Carl Ritter, da cátedra de Geografia da Universidade de Berlim, fundador dos estudos regionais de identificação das individualidades dos lugares e comparação das relações causais, contribuiu para as divisões regionais pautadas em critérios naturais e não em limites administrativos e políticos como se faz contemporaneamente. Embora o conceito de região passe por constantes críticas, o problema das disparidades regionais do desenvolvimento torna região tema presente sempre, com novos modelos de regionalizações, sobretudo por ser ferramenta de governos na implantação das ações.

A dimensão global salienta o valor do lugar, dá importância às políticas, mostra desgaste e esvaziamento das macropolíticas e das macrorregiões, além do descrédito de políticas concentradas. As macrorregiões aglomeram população, instalações produtivas, infraestruturas urbanas e econômicas, cooptando áreas rurais, e incorporam assentamentos humanos. A rapidez do crescimento faz surgir regiões metropolitanas do mundo industrializado. São consideradas as maiores na América Latina: Cidade do México, São Paulo, Buenos Aires e Rio de Janeiro e outras em escalas menores. Têm-se regiões no contexto de países, estados e municípios, em diversas escalas. Assim, região é conceito caro à Geografia, sendo habilidade geográfica regionalizar, compartimentar espaços para trabalhá-los em porções menores e alcançar objetivos localizados, chegando às comunidades. Há os que cristalizam região, tornando-a apenas palco, e os que a entendem como espaço ou território político. Trata-se de prática de controle e domínio do espaço em todos os países, mas o global, o nacional e o regional realizam-se em lugares, tornando a escala prioritária. Diz o Professor Milton Santos (2000) que mundo é abstração, pois todos os processos ocorrem em lugares.

Neste estudo, repensam-se região, desenvolvimento regional e comunidades, pelo exame de questões de solidariedade e resistências sociais nas relações com o turismo. Busca-se entender a importância do turismo no processo de desenvolvimento regional e local, a contribuição na geração do trabalho e na práxis social nas regiões e núcleos receptores de turismo, aproximando-se de microterritórios, aqui chamados de comunidades.

\section{Região e interesse pelo regional}

$\mathrm{Na}$ conjuntura política contemporânea, o interesse por realidade regional sobrepõe-se ao global e nacional, pois na região e no lugar é que se articulam 
formas de resistência às imposições do mercado globalizado. Conforme Corrêa (1997), há que se distinguir região natural de região cultural: a natural é tida como "porção da superfície terrestre identificada por uma especifica combinação de elementos da natureza: clima, relevo, vegetação, combinação que vai produzir a paisagem natural" e a cultural é "área de ocorrência de uma mesma paisagem cultural" (CORREAA, 1997, p. 184). Vidal de la Blache afirmava que a "região existe por si mesma, é autoevidente e cabe ao pesquisador reconhecê-la por meio de análises", informa Lencioni (1999, p. 201). Os conceitos de base positivista e naturista vão sendo superados com o surgimento de outros.

De acordo com Cunha (2012), na tese Pontos de visão e explorações historiográficas da abordagem regional: exercício a partir do Cariri cearense, nos Estados Unidos desenvolveu-se a "Regional Science", com visão dos alemães Von Thunen, Weber, Losch e Christaler, enquanto na escola francesa comandada por François Perroux, as explicações sobre região se fortaleciam com os trabalhos de Myrdal, Hirschmann e Claval. As regiões naturais servem de base à divisão regional do Brasil da década de 1940, adotada pelo IBGE. Para Duarte (1980, p. 14), o "movimento político-intelectual a partir da economia influi nos estudos geográficos sobre regionalização, estimulando o retorno do regional, agora com a ideologia desenvolvimentista”. O autor tem que Friedman, em 1977, mostra ser regionalização um processo de integração espacial cuja consequência é o desenvolvimento econômico. Nessa compreensão, região é tida não mais de forma positivista, mas com visão critica, levando Duarte (1980) a afirmar que:

As regiões passam a ser consideradas unidades espaciais em diferentes níveis de desenvolvimento ou modernização, e se relacionam entre si e dentro da organicidade global. (DUARTE, 1980, p. 16).

Não são acidentes geográficos ou objetos concretos da superfície da terra: são produções políticas, construções mentais de esquemas delineados por geógrafos, técnicos e políticos de atuação sobre a realidade. Diz Guimarães (1963, p. 302): "ao se fazer uma divisão regional em graus sucessivos de subdivisões, chega-se a pequenas áreas, cada uma das quais, dotadas de certa unanimidade." A modernidade política e as determinações de planejamento econômico terminam por minimizar as caracterizações homogêneas de espaços a serem regionalizados, com subordinação às divisões políticas administrativas, prevalecendo as intenções projetadas para esses espaços. Assim, a regionalização turística do Ceará agrupa praias com serras e sertão, ou seja, espaços heterogêneos, contrariando a formação da região natural que exige homogeneidade.

Data do final da década de 1950 o surgimento do conceito de regionalização, isto é, procedimentos operacionais de divisão regional de territórios. E assim região funcional ou urbana é considerada por Duarte (1980 p. 14) local ideal "para 
operacionalização das estratégias para se atingir o desenvolvimento”, e, nos países desenvolvidos, o planejamento faz-se em regiões urbanas ou organizadas e, nos de vida urbana menos estruturada, as regiões formais dizem-se bases espaciais de planejamento regional.

Cunha (2012) e Duarte (1980) mostram muitas perspectivas de regionalização, sendo uma das ultimas abordagens a "regionalização como totalidade social" que relaciona região como produto da sociedade e o explica pelo método dialético, mediante conceitos de modo de produção e de formação socioespacial. A concepção de cientistas críticos é avanço na ideia de região, com nivelamento ao conceito de território, como totalidade social e organização do espaço como totalidade. Assim, região contém sociedade e em especial toda a ideologia que perpassa as políticas de regionalização, sendo, então, para Duarte (1980, p. 16):

Um processo que leva a integração espacial, como consequência do desenvolvimento econômico. Da integração espacial evolui para espaço regionalizado como totalidade. $\mathrm{E}$ assim as regiões passam a ser consideradas unidades espaciais em diferentes níveis de desenvolvimento ou modernização, que se relacionam entre si dentro da organização global.

A partir da década de 1970, surgem abordagens diferenciadas de explicação de região e regionalização atreladas à abordagem geográfica, de tendência humanista, que entende ser o objeto da geografia regional o sistema relacional de ligação de grupos e indivíduos, associada a pesquisadores para produção de ideias sobre o mundo natural, e os de tendência marxista que dizem ser região decorrência da divisão territorial do trabalho e do processo de acumulação capitalista. Assim, é importante para a Geografia o tema região e regionalização na discussão de interesses da sociedade contemporânea, em especial do turismo.

O regional intranacional é centro de discussões de políticas públicas que se organizam regionalmente, em escalas menores, que contemplam o cotidiano e conseguem dar respostas mais localizadas e próximas dos sujeitos. Tradicionalmente, região é parte do território nacional e analisada na abordagem espacial e física. Na concepção da Geografia crítica, ela é fruto de relações econômicas e sociopolíticas que se articulam e produzem território. Região não se explica por ela mesma, especialmente no mundo globalizado, e, ao admiti-la, articulações são necessárias. Regionaliza-se o espaço para atendimento de finalidades políticas com base em interesses e ideologias, daí regiões e regiões superpostas.

A política macroeconômica global passa por descrédito quando se trata da formulação de programas nacionais em favor da luta de pequenas regiões, levando-as à busca de soluções endógenas, para o que as lideranças vão 
absorvendo tecnologias, transformando lugares em "regiões de aprendizado" como parques tecnológicos, novos distritos industriais que fogem dos modelos tradicionais, clusters, programas e políticas alternativas locais de áreas rurais e urbanas. Também empresas exercem maior pressão sobre regiões e lugares, tornando-os competitivos (STORPER, 1994). Lembra Silva (2003), remetendo-se a Rallet, que as regiões são determinadas não apenas por características físicas, mas por organizações, e, sobretudo pela gestão do desenvolvimento, ao assegurar que:

As regiões e os lugares não querem ser identificados somente pela existência de características particulares e recursos passivos como, por exemplo: meio ambiente, recursos naturais, produção agrícola e industrial, sistemas de cidades e patrimônio histórico, como tradicionalmente acontecia com a teoria das vantagens comparativas, de localização e diferenciação regional. Cada vez mais os lugares e as regiões querem ser conhecidos pelos recursos ativos, dinamicamente construídos pela organização socioterritorial, pelas políticas e formas próprias da gestão do desenvolvimento local e regional, envolvendo e integrando diferentes setores, atuando em contextos abrangentes e competitivos. (SILVA, 2003, p. 9)

Clusters são exemplos de opções de desenvolvimento regional por oferecerem potenciais de criação não apenas de vantagens competitivas e de localização, mas por criarem e aproveitarem externalidades, priorizarem infraestruturas macias - capital social - trabalharem o conhecimento tácito cultura, sentimento de pertença, intuição, valores regionais, emoção, entre outros, para valorização humana. A ideia de clusters não remete apenas à economia, mas à filosofia voltada às pessoas e aos lugares. As regiões que não conseguem assimilar o processo de aprendizagem são chamadas por Storper (1994) "regiões perdedoras", fadadas à permanência no path dependency. A prosperidade e o desenvolvimento da região não são herdados, nem emanam somente de dotes naturais, nem exclusivamente da força de trabalho. Conforme Porter (1999, p. 58), "os fatores que contribuem para isso são as diferenças nos valores regionais, ou seja, a cultura, as instituições e a história local. Fatores diferenciados em cada lugar, região ou país". As regiões não deixam de ser fruto da própria globalização, como produção de formas de controle e gestão de espaços e pessoas. Os clusters podem ter objetivos outros, conforme conceitos, pois são muitas vezes manipulados e, às vezes, surgem rótulos com aparência de modernos, sem deixar de ser, porém, formas de manipulações de economias globais.

Territórios são meios e produtos das relações de força e de poder que se estabelecem de forma contraditória e articulada, criando regiões e lugares diferenciados. Na explicação de Santos (2002), existe uma guerra econômica entre lugares que passam a configurar-se locus de resistência, pelas diferentes capacidades, oportunidades e possibilidades, não somente de inserção do capital, 
como também de evolução das pessoas. É no lugar que o cotidiano se realiza na espoliação da força de trabalho, nos fluxos de mais-valia, na reestruturação produtiva da acumulação capitalista. O capitalismo industrial e financeiro comanda a "guerra de lugares" (SANTOS, 2002, p. 88), em termos fiscais, em plano global e local. Na compreensão de Silva (2003, p. 21), "a própria dinâmica externa força, dialeticamente maior dinamismo interno na perspectiva dos territórios". A contradição, na perspectiva positivista, faz emergir o discurso de que a região tende a morrer, em virtude da força homogeneizante da economia global. Entretanto faz parte da lógica capitalista a tendência simultânea à homogeneização e diferenciação, tal como Oliveira (1981) compreende:

No sistema econômico capitalista, apesar de existir a tendência para a completa homogeneização da reprodução do capital e de suas formas, sob a égide do processo de acumulação e centralização do capital, que acabaria por fazer desaparecer as regiões, essa tendência nunca chega a materializar-se de forma completa e acabada, pelo próprio fato de que a reprodução do capital é desigual e combinada (OLIVEIRA, 1981, p. 27).

Com efeito, o global faz emergir o regional e o local, fragmentos da globalização. O lugar como singularidade é o espaço onde o global se realiza. Cada lugar é, à sua maneira, o mundo, segundo Milton Santos (2000). O pensamento de Oliveira (1981) leva a entender que as regionalizações decorrentes da dinâmica em territórios são produzidas em processos de inclusão/exclusão, continuidade/descontinuidade, encaixe/desencaixe e horizontalidade/verticalidade, produzindo espacialidades e economias desiguais e combinadas. A esse respeito Soja (1993, p. 132) justifica que "a própria acumulação do capital produz o desenvolvimento e o subdesenvolvimento, como movimentos mutuamente determinantes do movimento desigual e conjunto do capital.".

A Teoria do Desenvolvimento Desigual e Combinado, explicada por Trotsky, ressalta as proporções no crescimento da vida social e a correlação concreta dos fatores desigualmente desenvolvidos e distribuídos no processo históricogeográfico. Como aspectos fundamentais, destaca: o projeto de realização do homem requer domínio sobre as forças produtivas, pois todo avanço histórico produz-se por crescimento rápido ou lento das forças produtivas, neste ou naquele segmento da sociedade e do espaço, em razão das diferenças de condições naturais e conexões históricas. As disparidades outorgam caráter de expansão ou compressão a toda época histórica e conferem distintas proporções de desenvolvimento a diferentes povos, variados setores da economia, às diferentes classes e instituições sociais e culturais. As variações entre múltiplos fatores da história no espaço dão base ao surgimento do processo de desenvolvimento social 
na escala humana, em constantes formações e renovações. São formações combinadas de formas contraditórias e peculiares (NOVAC, 1988, p. 9). Complementa Amin (1989), justificando a centralidade e a "periferização" do processo, pois enquanto o capitalismo central conhece a acumulação autocentrada, as formações sociais periféricas conhecem estrutura de desenvolvimento essencialmente desequilibrada. No centro, o desenvolvimento gravita ao redor da produção de bens de capital e de incentivo ao consumo de massa, enquanto, na periferia, a produção é voltada para a exportação e o consumo de bens de luxo que formam a base da economia, tornando a estrutura essencialmente desequilibrada. A abordagem centro e periferia na questão regional é entendida segundo a formação histórica de lugares, como regiões dominantes e regiões subordinadas. Daí as segregações socioespaciais subordinadas, podendo-se tomar como exemplo as regiões norte e nordeste do Brasil em relação ao centro sul.

$\mathrm{O}$ acesso aos bens depende do produzido na região, mas sobretudo da forma como são distribuídos os resultados da produção. As diversas leituras e interpretações de região, entretanto, têm em comum a noção de singularidade ou espacialidade diferenciada, que determina certa mobilidade em torno de projetos políticos e atividades econômicas variadas. A dificuldade em trabalhar região consiste no fato de que a delimitação física leva a petrificar a realidade, quando tudo é movimento, relação e correlação.

\section{Desenvolvimento regional}

O desenvolvimento regional fundamenta-se em especificidades locais e parte da premissa de que aquilo que é pensado para um lugar não deve, necessariamente, ser para outro. O turismo pode ser atividade viável e impulsionadora do desenvolvimento para determinada região e não ser para outra. Explica Albuquerque (1998, p. 137) que o nível de planejamento implica o "compromisso de uma parte significativa da sociedade para adesão às mudanças básicas, assim como atitudes e comportamentos que permitam a substituição da concepção tradicional do espaço como simples cenário físico, pela concepção de um contexto social de cooperação ativa do território". Volta o interesse para economias localizadas, enfatizando as dimensões sociopolíticas, culturais, valores e instituições locais.

Promover a região não significa isolá-la, nem defender autossuficiência, mas requer políticas que fortaleçam e qualifiquem suas estruturas internas, tornando-as abertas, mesmo sob influência de contradições da economia de mercado. Souza (1997) mostra a importância do desenvolvimento regional, justificando-o em face da aceleração do processo de urbanização, que evidencia maior intensidade na estruturação das regiões; da existência de fatores a serem programados positivamente a fim de participar no processo de desenvolvimento que extravasa o 
âmbito local, com implicações no plano nacional. A região constitui, assim, nível de integração de realidades diversas, geoambientais, econômicas, demográficas, educacionais, administrativas, integradas ao processo de desenvolvimento global. O desenvolvimento regional transcende a versão integradora, na medida em que ressalta vetores da transformação regional baseado no tripé que tem por base o território, onde grupos sociais se enraízam e por cuja base estabelece o enredamento entre diferentes lugares e setores econômicos que instituem sistema organizacional fundamentado na cooperação e na coesão. Quanto mais forte o nível de articulação na região, tanto mais essa tende a se desenvolver. Assim, o desenvolvimento regional entendido como forma de melhoria de lugares significa transformação política pelos e para os habitantes, em espaço coletivo produzido por exigência da qualidade de vida dos residentes e não apenas em função das empresas.

O desenvolvimento regional é voltado para lugares e passa pelo fomento a programas para transformação e por projetos articulados contemplando diversas atividades econômicas, como agricultura, pesca, artesanato, pequenas indústrias, lazer e turismo, entre outras ações, favorecendo créditos a microempresas, e, sobretudo, promovendo o crescimento e participação de pessoas. Trata-se de proposta de planejamento diferenciado, resultado da práxis social coletiva. Lembra Silva (2003) que, "para responder a estes desafios, é preciso sempre estudar a resiliência dos territórios aos choques da globalização expressa nos movimentos de coesão e solidariedade em busca de objetivos comuns". Nessa concepção, constata-se que o crescente nível de organização de comunidades em pequenos territórios busca soluções locais que emergem do processo simultâneo de resistência a conflitos com base na solidariedade. Acrescenta o pesquisador de estudos regionais que:

A endogenia está na capacidade organizacional das comunidades locais e regionais definirem prioridades e formas de ação inovadora que possam dinamizar as atividades econômicas, sociais, políticas e culturais em busca de patamares mais elevados (SILVA, 2003, p. 23).

Nos últimos anos, houve mundialmente valorização de políticas locais concebidas como possibilidade de dinamização de territórios subordinados: espaços interiores, rurais, mais distantes das grandes metrópoles. Os governos valem-se de planos de integração de ações, como mecanismo de crescimento, concebem futuro desejável para o lugar e identificam meios necessários de alcançá-lo, descobrindo prioridades e integrando as atividades econômicas. $\mathrm{O}$ desenvolvimento passa a ser mais abrangente e menos econômico, mais socioespacial, referindo-se ao desenvolvimento territorial que remete a questões políticas, culturais e sociais desiguais e combinadas regionalmente. Promover o desenvolvimento regional é desafio em todos os países e constitui tentativa de 
dar respostas aos problemas econômicos, romper com a falta de trabalho que origina graves problemas socioespaciais, para promoção de desenvolvimento que ofereça oportunidades generalizadas e democráticas.

Muitos lugares são afetados pela ocupação intensiva de exploração industrial que acelera problemas sociais, econômicos e ambientais. Assim, o objetivo do desenvolvimento regional é encontrar formas de inserção de lugares na economia de mercado, sem necessariamente desvalorização do homem, lugares, patrimônio cultural e natural. Manter ambientes habitáveis, promover o desenvolvimento com menores conflitos socioeconômicos e condições de vida dignas para residentes da maioria dos lugares, com projetos turísticos menos conflitivos e mais sustentáveis, é uma opção de modelo de desenvolvimento, não copiado de países ricos, que leva em consideração aspectos territoriais, temporais, culturais e patrimoniais engendrados por lideranças, pactos, parcerias, programas e projetos de articulação do espaço pelos habitantes. Levam-se em consideração especificidades do local na orientação de estratégias de ação e seguem caminhos próprios, sem modelos preconcebidos, com planos e projetos em conformidade com a realidade.

A dinamização do potencial regional passa, antes de tudo, pelas ações de apoio à população em estratégias de descoberta de forma autônoma de produção, crescimento e caminho próprio, questionando as soluções prontas de cima para baixo (DOWBOR, 1996). A capacidade política não dispensa condições favoráveis de modo a aproveitar as características peculiares e as riquezas de cada território e região para superar a crise capitalista, sobrepondo-se ao processo econômico de única via baseada na indústria e nos grandes núcleos urbanos. Assim, baseia-se na flexibilidade, com adaptação à realidade do lugar, como mostra Albuquerque (1998, p. 137), ao expressar que:

As estratégias do desenvolvimento local não são nem um posicionamento autárquico, nem o resultado de uma mistificação do pequeno e do marginal. Trata-se, ao contrário de um enfoque que pretende integrar formas subordinadas de acumulação de capital que protagonizam aquelas frações do mesmo, cujos mercados não se explicam exclusivamente pelo fenômeno da transnacionalização dos grandes grupos, que funcionam segundo uma lógica que, apesar de ser hegemônica em nível mundial, não dá conta do todo.

Os sujeitos sociais que participam do desenvolvimento regional utilizam poderes de forma diferenciada: setor privado, Estado e sociedade civil. O primeiro representado pelas empresas que, na maioria das vezes, domina as relações sociais, por deter o poder econômico. O Estado coaduna-se com imperativos do mercado; utiliza as mesmas lógicas do mercado. A sociedade enfrenta e partilha o processo hegemônico de forma subordinada, e, embora maioria, tem sempre 
menor poder de decisão, apesar de exercer pressão política em determinados momentos. Mas a responsabilidade maior é do Estado. Santos (1988, p. 17) mostra que o crescimento econômico está associado ao poder político, à cultura de massa, à "cientificização" da burocracia, à centralização das decisões e da informação que acirram as desigualdades entre países e regiões.

No capitalismo, o Estado participa direta ou indiretamente do modelo de desenvolvimento hegemônico. Villasante (1998, p. 55), referindo-se a situações similares na América Latina, lembra que a perspectiva do lugar e da região não significa desconhecer a presença do Estado e da mundialização do capital, pois não se trata de desconectar-se dessas realidades, mas implica voltar a política estatal para interesses de economias populares dentro de lógicas alternativas.

O regional representa uma instância em que grupos sociais realizam ações vinculadas aos processos globais, em parte, como é pensamento de Amin (1989), "as ações locais ultrapassam o âmbito local, dependem às vezes de ações exógenas e que é assim que a região se insere no global". Santos (2002) alerta para o fato de que a relação global/local não deve ocorrer de forma tão submissa. Nesse sentido, lembra Arruda (1996, p. 3): a globalização por si mesma não é problemática, pelo contrário, é um progresso na história da humanidade. O problema é a forma como acontece, pois impõe aos países e povos, sobretudo aos do hemisfério sul, a lógica de desenvolvimento exógena e um modelo subordinado de inserção na economia global, criando obstáculos ao exercício da cidadania. Proposta específica para as regiões precisa considerar as contradições, salvaguardando diferenciais, ou seja, o que faz o lugar único. Nesse contexto, podem ser implementadas atividades complementares de geração de trabalho e ocupação, abrindo espaço para o turismo; não o turismo dos grandes empreendimentos, dos resorts, mas voltado a pequenos negócios, com resultados socializados e próximos das populações. No turismo de comunidades, os serviços ofertados de pequenas pousadas, restaurantes, venda de souvenires inserem-se na sua cadeia produtiva.

Ressalte-se que a implantação de investimentos em comunidades nem sempre traz desenvolvimento para a região. Em muitos casos, trata-se apenas da localização específica de certos investimentos ligados às economias externas e não à economia local, cujos lucros se remetem para fora, e que voltam às matrizes, circulando apenas em redes fechadas de cadeias hoteleiras. A indústria multinacional, ou resort, quando em pequeno lugar ou comunidade, emprega poucas pessoas, alegando falta de capacitação, sem assumir compromisso social, sem capacitar residentes para o trabalho, pouco contribuindo com a região e com o lugar. Muitas vezes, empresas ficam liberadas de impostos por anos, recebem subsídios de governos, são isentas de fiscalização ambiental ou de qualquer exigência que as façam assumir responsabilidade social em contrapartida aos impactos negativos causados. 
Grande parte de empresários e empreendimentos não se compromete com as regiões onde se alocam, projetam atividades de fora para dentro, procuram benefícios para as empresas, desconsiderando a população residente. O lugar serve muitas vezes de mero suporte físico, de receptor de dejetos, detritos e da poluição indesejada. É assim que indústrias de países ricos agem ao se transferir para países periféricos. Chegam às regiões pobres, além das fábricas e oficinas sujas, lixo e trabalho escravo, lado desumano do processo produtivo. O subemprego ampliase, pois, no Brasil, o salário mínimo tem níveis irrisórios, se comparado ao de países ricos.

O turismo, muitas vezes, é mais uma forma de exploração de belezas naturais de países pobres, especialmente de regiões tropicais que, dependentes de avanços tecnológicos, são detentoras de áreas naturais menos degradadas e não tão fortemente atingidas pela poluição. E, assim, contraria a promoção do desenvolvimento regional, cujos trabalhos não fazem crescer a economia local, nem valorizam o homem, nem sua decisão, autonomia, mas apenas legitimam experiências do Estado, sem proporcionar melhoria de vida à maioria dos residentes. Isso significa omitir-se na promoção e produção da riqueza regional e da redistribuição da riqueza de forma solidária, partilhada e justa.

Partilha, segundo enfoque burguês, é confundida com assistencialismo, diferentemente de teorias críticas que a entendem como justiça social. Existe, pois, o dar contaminado pela vontade de poder sobre o outro, que busca dominação e mesmo opressão de indivíduos e povos. É partilha de aparência. Existe processo solidário que busca satisfação e prazer do próprio ato de partilhar, de expressão egoísta, e, em geral, percebida por quem recebe como humilhação ou ofensa. Existe o dar utilitarista, em certas tendências de políticos que no fundo buscam proveito próprio, lucro, barganha. Assim, esse dar não cria mentalidade nova. Existe, por fim, partilha que se abre ao outro, indivíduo ou povo, e feita respeitando dignidade, costumes, cultura e tradição. É assim que Araújo (1998, p. 20) se refere à cultura da partilha. A cultura do doar - filosofia da economia solidária, da economia de comunhão - se afina com as políticas participativas desejadas pelas comunidades. O professor Dowbor (1996, p. 9) mostra também de forma muito clara a filosofia das políticas de desenvolvimento regional, dizendo que

Não há grandes mistérios quanto ao que queremos como sociedade: a segurança do necessário para uma vida digna, a tranquilidade no relacionamento social, o sentimento de participar criativamente das coisas que acontecem, a liberdade moderada pelas necessidades, a paz do amor, o estímulo do trabalho, a alegria de rir com os outros, o realismo de rir de si mesmo. Mas, estes objetivos passam por um valor essencial que precisa ser resgatado: a solidariedade humana. 
O desenvolvimento regional é o local, pois é o lugar das pessoas - com seu modo próprio de ser e sentir, com tradições religiosas, artísticas, passado histórico, costumes típicos, "estilo" de vida familiar e social, atividades produtivas com problemas, necessidades e aspirações próprias, sobretudo com consciência coletiva de vida em comum - forma de solidariedade regional e local.

Cidades, vilas, distritos, menores núcleos urbanos, lugares e territórios apropriados à implementação, estímulo e diversificação de crescimento de políticas regionais, além de criar empregos, elevam a autoestima, a criatividade e o poder aquisitivo das famílias. Trata-se de proposta difícil, mas animadora, por propor mudanças radicais e promoção do homem. Cumpre pensá-la na visão de Furtado (1974, p. 30), que ensina:

Somente a criatividade política impulsionada pela vontade coletiva poderá produzir a superação desse impasse. E essa vontade coletiva só poderá surgir se der um reencontro das lideranças políticas com os valores permanentes de cultura, cujas raízes estão na massa da população. Portanto, o ponto de partida do processo de reconstrução que temos pela frente terá que ser uma maior participação do povo no sistema de decisão.

As atividades humanas têm como pressuposto fundamental a comunidade, território, lugares de pequena dimensão que oferecem condições para a solidariedade orgânica, porque seu principal objetivo é atingir a escala humana. Muitos exemplos de desenvolvimento macroeconômico mostram-se incapazes de atingir setores marginalizados, de situar o homem como principal beneficiário do processo e respeito aos direitos. Apesar disso, para Santos (2000, p. 14) há tendência de mudança:

Estamos convencidos de que a mudança histórica em perspectiva provirá de um movimento de baixo para cima, tendo como atores principais os países subdesenvolvidos e não os países ricos; os deserdados e os pobres e não os opulentos e outras classes obesas; o indivíduo liberado partícipe das novas massas e não o homem acorrentado; o pensamento livre e não o discurso único.

Problemas regionais diversos esperam soluções. A acelerada redução do trabalho, chegando à forma de desemprego e exclusão, contraditoriamente, aponta para nova proposta de desenvolvimento regional, do nível aqui proposto, com redução de disparidades regionais e opções de práticas participativas e democráticas, além de mecanismos voltados para a articulação de sujeitos sociais, priorizando as pequenas escalas regionais. 


\section{O turismo e as resistências de comunidades}

O turismo, na contemporaneidade, faz parte da força produtiva regional, participa no crescimento regional de forma desigual pelos territórios, assimilado de forma diferenciada por regiões e territórios, originando processos que distribuem e concentram riquezas, aumentam ou diminuem formas de exploração. No modelo econômico vigente, o aumento do desemprego, da fome e da pobreza de muitas regiões está associado à elevação das bolsas de valores e aumento da riqueza de outras regiões em qualquer lugar do mundo. Soja (1993, p. 103) apoia-se em Mandel para explicar a relação desenvolvimento e capitalismo, afirmando que "o desenvolvimento desigual entre as nações e regiões é a própria essência do capitalismo, no mesmo plano da exploração da mão de obra pelo capital". A exploração se faz em nível de indivíduos e lugares, ou seja, o capital seleciona trabalhadores e lugares. O turismo, como atividade capitalista, oferece inúmeras oportunidades de exploração, não só de mão de obra, como de lugares, e qualquer processo produtivo capitalista passa pela lógica, com difícil fazer contraponto ao modelo global.

Faz-se necessário reconhecer que o turismo é uma política vinculada à política macroeconômica, atividade decorrente de imposições do modo de vida moderno que prioriza as necessidades do capital em processo contraditório de enfraquecimento do Estado, mas fortalece os movimentos sociais e a democracia, ampliando a exclusão e a pobreza na medida em que amplia os espaços de participação. Assim, juntamente com o eixo do turismo convencional, emerge o do turismo comunitário, representando estratégias de sobrevivência baseadas na criatividade humana e no uso de tecnologias, como forma de inclusão no trabalho. Como atividade reestruturadora das crises econômicas industriais, os serviços tomam aparente vanguarda entre as atividades econômicas atuais e o turismo aparece como de grande destaque.

As atividades turísticas comunitárias são associadas às demais atividades econômicas com iniciativas que fortalecem agricultura, pesca e artesanato, fazendo-os atividades preexistentes ao turismo. Prioriza a geração de trabalho de residentes, pequenos empreendimentos, dinamização do capital local, a garantia da participação de todos. Assegura a participação de pessoas de comunidades com o planejamento descentralizado e associativo, luta pela regulamentação fundiária de terras litorâneas, muitas de marinha, pela garantia de posse pelas populações indígenas, pesqueiras, chamadas comunidades nativas.

No entanto, ao lado do desenvolvimento dos resorts, da rede hoteleira e da concentração de renda, existem experiências bem sucedidas de atividades turísticas com características populares, voltadas ao desenvolvimento social, com maior distribuição da riqueza, com nomes variados: turismo comunitário, turismo solidário, turismo de base local, de economia solidária, turismo alternativo. $\mathrm{O}$ 
importante nas experiências é vislumbrar mais possibilidades de comunicação e inclusão de comunidades em práticas positivas que o turismo pode dinamizar. Os exemplos se multiplicam no contexto de mercado global, tendo em vista maior participação de lideranças em "nichos" que favorecem pequeno e micro empreendedores na cadeia produtiva do turismo.

\section{Referências}

ALBUQUERQUE, Francisco. Desenvolvimento econômico local e distribuição do progresso técnico. Fortaleza: BN, 1998.

AMIN, A. Flexible specialization and small firms in Italy: myths and realities. v. 21, n. 1, p. 13-34. Antipode, 1989. Wiley Online Library.

ARAÚJO, Vera. Economia de comunhão e comportamentos Sociais. In: COSTA, Rui. et al. Economia de comunhão. São Paulo: Cidade Nova, 1998.

ARRUDA, Marcos. Globalização e sociedade civil - repensando o cooperativismo no contexto da cidadania ativa. Perspectiva Econômica, São Leopoldo/RS, v. 32, n. 96, jan-mar., 1996.

AUGÉ, Marc. Não lugares: introdução a uma antropologia da super modernidade. Campinas: Papirus, 1994.

CORREA, Roberto L. Região: a tradição geográfica. In: CORREA, Roberto L. Trajetórias geográficas. Rio de Janeiro: Bertrand Brasil, 1997.

CUNHA, Maria Soares da. Pontos de visão e explorações historiográficas da abordagem regional: exercício a partir do Cariri Cearense: (séculos XIX e XX). Tese (Doutorado em Geografia) - Departamento de Geografia da UFC. Fortaleza, 2012.

DUARTE, Aluizio Capdeville. Regionalização: considerações metodológicas. Associação de Geografia Teorética. Boletim de Geografia Teorética, Rio Claro/SP, ano 10, n. 20, p. 32, 1980.

DOWBOR, Ladislau. Da globalização ao poder local: a nova hierarquia dos espaços. In: FREITAS, Marcos Cézar. A reinvenção do futuro. São Paulo: Cortez, 1996. 
A reprodução social: propostas para uma gestão descentralizada. Petrópolis: Vozes, 1998.

FURTADO, Celso. O mito do desenvolvimento econômico. Rio de Janeiro: Paz e Terra, 1974.

GUIMARÃES, Fábio de Macedo Soares. Observações sobre o problema da divisão regional do Brasil. Revista Brasileira de Geografia, Rio de Janeiro, ano XXV, n. 3, jul./set. 1963.

LENCIONI, Sandra. Região e geografia. São Paulo: USP, 1999.

NOVAC, George. A lei do desenvolvimento desigual e combinado da sociedade. Trad. Valdemir Lisboa Santos. São Paulo: Rabisco, 1988.

PORTER, Michel E. Competição. Rio de Janeiro: Campus, 1999.

OLIVEIRA, F. Elegia para uma re(li)gião. Rio de Janeiro: Paz e Terra, 1981.

SANTOS, Milton. Metamorfose do espaço habitado. São Paulo: Hucitec, 1988.

Por uma outra globalização. Do pensamento único à consciência universal. Rio de Janeiro: Record, 2000.

SANTOS, Milton; RIBEIRO, Wagner Costa; GONÇALVES, Carlos Walter Porto. O país distorcido: o Brasil, a globalização e a cidadania. São Paulo: Publifolha, 2002.

SILVA, Sylvio Carlos Bandeira de Melo; SILVA, Bárbara-Christine N. Estudos sobre a globalização, território e Bahia. Salvador: UFBA, 2003.

SOJA, Edward W. Geografias pós-modernas: a reafirmação do espaço na teoria sócio-crítica. Trad. Vera Ribeiro. Rio de Janeiro: Zahar, 1993.

SOUZA, Marcelo José L. de. Como pode o turismo contribuir para o desenvolvimento local? In: RODRIGUES, A. A. B. Turismo: desenvolvimento local. São Paulo: Hucitec, 1997.

STORPER, Michael. Desenvolvimento territorial na economia global do aprendizado: o desafio dos países em desenvolvimento. In: RIBEIRO, Luiz C. de Queiroz.; SANTOS JUNIOR, Orlando A. dos (Orgs.). Globalização, fragmentação e reforma urbana: o futuro das cidades brasileiras em crise. Rio de Janeiro: Civilização Brasileira, 1994. 
VILLASANTE, Tomás R. Del desarrollo local a las redes para mejor-viver. Buenos Aires: Lumen/Humanitas, 1998.

Endereço para correspondência:

Lu₹ia Neide Menezes Teixeira Coriolano - luzianeidecoriolano@gmail.com Avenida Paranjana, 1900, Campus do Itaperi

60740-000 Fortaleza/CE, Brasil

Fábio Perdigão Vasconcelos - fabioperdigao@gmail.com Avenida Paranjana, 1900, Campus do Itaperi 60740-000 Fortaleza/CE, Brasil 